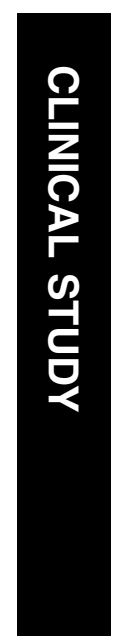

\title{
Effects of fibrovascular traction and pooling of tears on corneal topographic changes induced by pterygium
}

Abstract

Aim To investigate the effects of fibrovascular traction and the pooling of tears at the pterygium apex on the corneal topographic changes induced by pterygium.

Methods A total of 16 eyes of 14 cases with primary pterygium were included in the study. A computerized corneal topography system was used for corneal topography examinations. Baseline keratographs were taken two times at straight gaze. A repeat corneoscope photograph was immediately obtained in temporal gaze. Then the tears at

${ }^{1}$ Department of Ophthalmology School of Medicine Yuzuncu Yil University Van, Turkey

\section{${ }^{2}$ Department of} Ophthalmology School of Medicine Kahramanmaras Sutcuimam University 46050 Kahramanmaras Turkey

Correspondence: Dr M Ozdemir Tel: + 903442152465 Fax: + 903442212371 E-mail:drmozdemir@ hotmail.com

Received: 12 November 2001

Accepted: 7 August 2002

This study has been presented at the XIVth Congress of the European Society of Ophthalmology, Istanbul the pterygium apex were dried with a cellulose sponge, and a new corneoscope photograph was immediately obtained without allowing one to blink. Corneal topographic maps (numeric maps) were divided into 301 fields in 24 meridians. One colour was allocated to each field, representing its mean refractive power for all groups. In all eyes, keratometric astigmatism at the $3 \mathrm{~mm}$ central cornea and total mean corneal refractive power were found. Data were compared using pairedsamples two-tailed $t$-tests.

Results Keratometric astigmatism at the $3 \mathrm{~mm}$ central cornea was significantly reduced at the temporal gaze $(3.10 \pm 2.34 \mathrm{D}, t=3.40, P=0.027)$ and dried eyes $(2.12 \pm 1.01 \mathrm{D}, t=4.74, P=0.001)$ according to the first baseline measurement $(4.31 \pm 1.91 \mathrm{D})$ of the total mean corneal refractive power was found to be $43.45 \pm 1.28 \mathrm{D}$ (39.29-45.87) at the first baseline measurement. There was no change at the temporal gaze $(43.54 \pm 1.06 \mathrm{D}, P>0.05)$. However, the total corneal refractive power was significantly higher in dried eyes $(44.26 \pm 0.93 \mathrm{D}, t=34.92$, $P<0.001)$. The steepest region of corneal topography was a superior quadrant, and the
T Yasar', M Ozdemir², A Cinal'1, A Demirok', B Ilhan' and AC Durmus ${ }^{1}$ flattest area was a nasal quadrant at the baseline. At the temporal gaze, the cornea was significantly flatter in the superior and inferior sides of the pterygium meridian. After dried pooling of tears, topographic abnormalities returned, and the cornea became more uniform and symmetric.

Conclusion We conclude that the pooling of tears at the pterygium apex plays an important role, but fibrovascular traction has no effect on the corneal topographical changes induced by pterygium.

Eye (2003) 17, 492-496. doi:10.1038/

sj.eye. 6700377

Keywords: pterygium; pooling of tears; fibrovascular traction; corneal topographic changes; computerized corneal topography

Introduction

Pterygium is a fibrovascular tissue invading the superficial cornea. The cornea shows destruction of Bowman's layer by fibrovascular ingrowth. Pterygia usually locate in the nasal quadrant and interpalpebral space, and it is frequently bilateral. ${ }^{1,2}$ Pterygia presented cosmetic problems, visual impairment, and irritation. ${ }^{3}$ The aetiology of the pterygium is not completely known. However, strong correlation with ultraviolet exposure has been documented, although dryness, inflammation, and exposure to wind and dust or other irritants may also be factors. ${ }^{4,5}$

Pterygia may lead to visual impairment invading the visual axis or distorting central corneal topography, and induce a focal corneal flattening and severe astigmatism demonstrated by an increasing ovality of corneoscope mires in 
the meridian of the pterygium. ${ }^{6-10}$ The reason for this astigmatism has not been found yet. A possible cause could be local pooling of tears at the pterygium apex. ${ }^{6}$ Such pooling may be indicative of the corneal flattening. Another possible cause may be the exertion of traction forces by contractile elements within the pterygium that mechanically distort and flatten the cornea. ${ }^{7,11}$

Myofibroblast cells within the granulation tissues are specific ultrastructural cells and have contractile, capability. An ultrastructural study has revealed that there are no myofibroblast cells within pterygium tissue. $^{6}$

In this study, we investigate the effects of fibrovascular traction and the pooling of tears at the pterygium apex on corneal topography using a computerized corneal topography system.

\section{Materials and methods}

A total of 16 eyes of 14 cases with primary pterygium $3 \mathrm{~mm}$ and above were included in the study. Patients with a history of ocular surgery, ocular trauma, contact lens wear, keratoconus, or anterior segment diseases other than primary pterygium were excluded.

All pterygia were located in the nasal quadrant. The mean pterygium length was found to be $3.64 \pm 0.86 \mathrm{~mm}$ (3.00-5.00 mm). Pterygium sizes were measured using a Castroviejo caliper and a slit-lamp biomicroscope on the horizontal meridian.

All cases underwent an examination including a complete history and manifest refraction. Applanation tonometry, artificial tears, or artificial means of opening the eyelid (use of an eyelid speculum) were not permitted before or during topography using the Corneal Analysis System (CAS) (EyeSys Laboratories, Inc., version 2.1). CAS software provides a 24-meridian numeric map with 301 points. The map covers $10 \mathrm{~mm}$ of central cornea.

Videokeratographs were taken by having the patient place his/her chin on the chin rest and fixate on a green fixation light using the target eye. Blinking was allowed, except just before the image was captured on the computer. Image quality was evaluated by assessing the completeness and continuity of the rings.

Videokeratographs were taken in the same examination room, under the same lighting conditions, and by the same experienced ophthalmologist.

Videokeratographs were taken under topical anaesthesia with $0.4 \%$ oxibuprocaine. Baseline keratographs were taken two times to evaluate the accuracy of tests. Then, without removing the patient's head from the corneoscope, a repeat corneoscope photograph was immediately obtained in temporal gaze.
Next, the tears at the pterygium apex were dried with a cellulose sponge. Finally, a new corneoscope photograph was immediately obtained without allowing one to blink. When necessary, the patient's eyelids were opened by a resident.

For taking temporal gaze topographies, we turned the patient's head by about $45^{\circ}$ while he was looking at the centre of the fixation light.

\section{Data analysis}

Corneal topographic maps (numeric maps) were divided into 301 fields in 24 meridians. For output, a diagram with 301 fields was constructed, representing corneal topography. The refractive values of the 301 defined points of the numeric map were allocated to the respective fields. The values of refractive power in each of the 301 corneal fields of 16 eyes were stored.

We allocated one colour to each field, representing its mean refractive power for all groups. In this way, we produced a colour-coded map showing the distribution of the mean refractive power of patients throughout the cornea. We also compared the refractive power of each field of all the assessments, and the significance levels of the paired $t$-tests were superimposed on the colour-coded map.

Keratometric astigmatism at the $3 \mathrm{~mm}$ central cornea and the total mean refractive power of the whole cornea were calculated for all eyes.

\section{Statistical analysis}

Data were expressed in dioptres as mean $\pm S D$ and compared using paired-samples two-tailed $t$-tests considering $P$ values less than 0.05 as statistically significant and $P$ values less than 0.001 as highly significant.

\section{Results}

The study included five males and nine females. The mean age was found to be $39.22 \pm 16.08$ years (23-70).

Keratometric astigmatism at the $3 \mathrm{~mm}$ central cornea was found to be $4.31 \pm 1.91 \mathrm{D}(1.22-5.84)$ at the first baseline, $4.26 \pm 1.79 \mathrm{D}(1.37-6.10)$ at the second baseline, $3.10 \pm 2.34 \mathrm{D}(1.00-6.21)$ at the temporal gaze, and $2.12 \pm 1.01 \mathrm{D}(0.96-3.10)$ at the dried eyes. The differences in keratometric astigmatism between two baseline values were not statistically significant $(t=0.63, P=0.570)$.

The differences in keratometric astigmatism between the first baseline and temporal gaze $(t=3.40, P=0.027)$, and between the first baseline and dried eye 
measurements were statistically significant $(t=4.74$, $P=0.001)$.

The mean positive astigmatic axis was found to be $79.40 \pm 4.56^{\circ}(74-84)$ at the first baseline measurements, $79.80 \pm 5.45^{\circ}(73-85)$ at the second baseline measurements, $81.80 \pm 8.61^{\circ}$ (70-93) at the temporal gaze, and $80.60 \pm 3.81^{\circ}(75-86)$ at the dried eyes. There was no statistically significant difference between these values $(P>0.05)$.

The total mean corneal refractive power was found to be $43.45 \pm 1.28 \mathrm{D}(39.29-45.87)$ at the first baseline measurements, $43.54 \pm 1.06 \mathrm{D}(40.40-45.17)$ at the temporal gaze, and $44.26 \pm 0.93 \mathrm{D}(42.45-47.42)$ at the dried eyes. Corneal refractive power did not significantly change at the temporal gaze $(P>0.05)$. However, it was significantly higher in dried eyes $(t=34.92, P<0.001)$.

When the figure established using average values of baseline corneal topographies was evaluated, the steepest region was the superior quadrant. Also, a region located at the inferior temporal close to the central point was steeper than the other regions. The cornea was flat especially at the midline and nasal quadrant, where the pterygium is located (Figure 1).

When the figure established using average values of temporal gaze corneal topographies was evaluated, the cornea was significantly flatter in the superior and inferior sides of the pterygium meridian (Figures 2 and 3).

After dried pooling of tears at the pterygium apex, the central cornea became steeper, flattening in the nasal quadrant returned, and the cornea was more uniform and symmetric (Figure 4). Corneal topographic changes were statistically significant at the bow-tie-shaped region on the horizontal line (Figure 5).

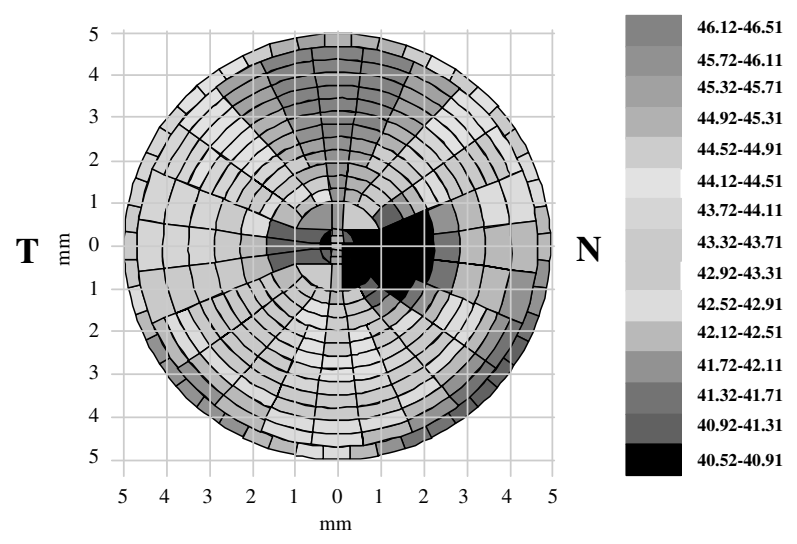

Figure 1 Mean refractive powers of the corneas with pterygium at the baseline (right eye, data were expressed as dioptric power, T: temporal side; N: nasal side).

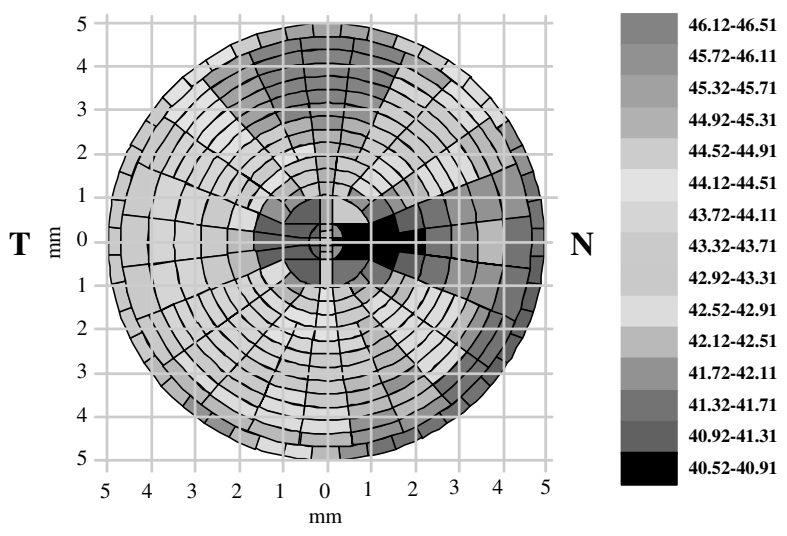

Figure 2 Mean refractive powers of the corneas with pterygium at the temporal gaze (right eye, data were expressed as dioptric power, N: nasal side; T: temporal side).

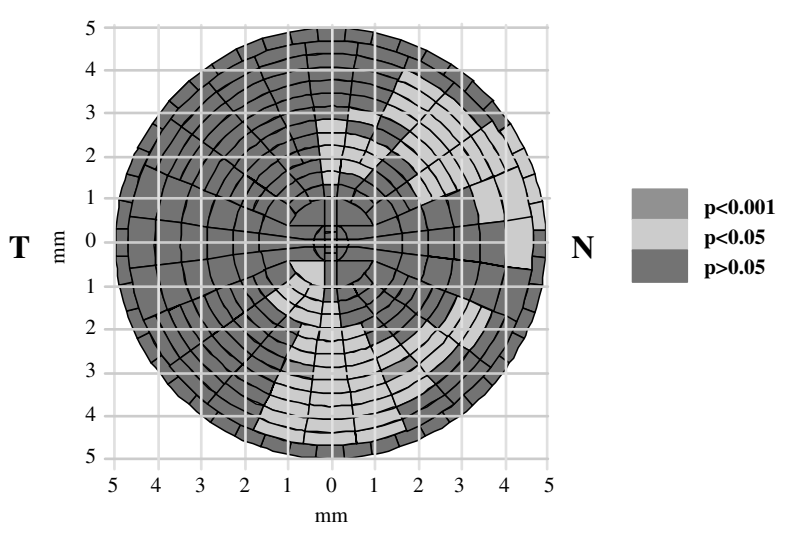

Figure 3 Results of statistical analysis of refractive changes between the temporal gaze and baseline $(P>0.05$ : insignificant changes; $P<0.05$ : significant changes; $P<0.001$ : highly significant changes; $\mathrm{N}$ : nasal side; T: temporal side).

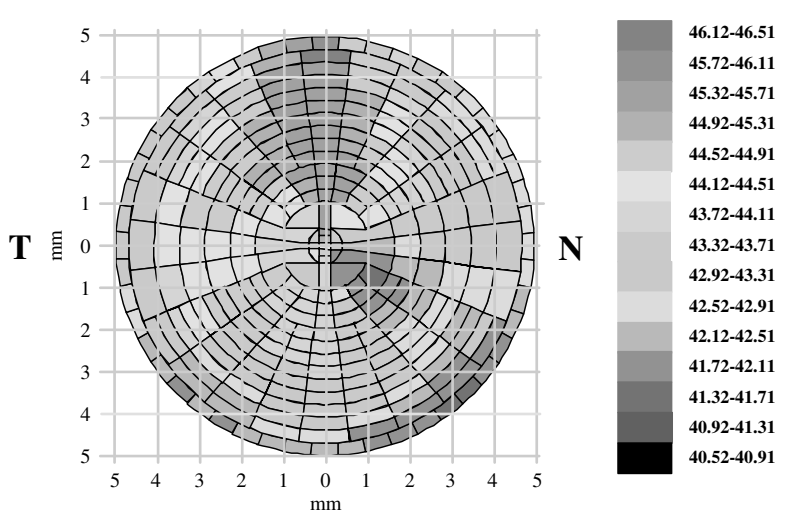

Figure 4 Mean refractive powers of the corneas with pterygium at dried eyes (right eye, data were expressed as dioptric power, N: nasal side, T: temporal side). 


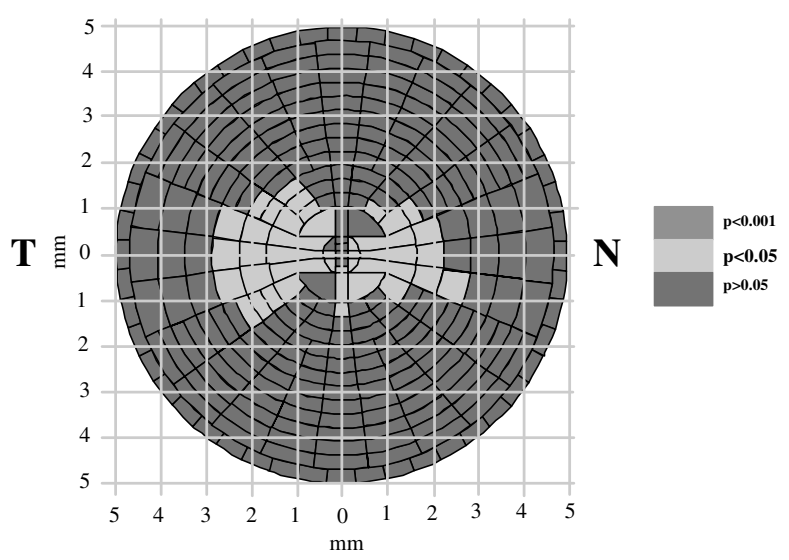

Figure 5 Outcomes of statistical analysis of refractive changes between baseline and dried eyes (right eye, $P>0.05$ : insignificant changes; $P<0.05$ : significant changes; $P<0.001$ : highly significant changes; $\mathrm{N}$ : nasal side; $\mathrm{T}$ : temporal side).

\section{Discussion}

Corneal topographic changes induced by the pterygium have been revealed in detail using a computerized corneal topography system. ${ }^{3,12-14}$ However, the mechanism of these changes is not known definitely. Three different hypotheses were suggested regarding this problem. Hansen and Norn ${ }^{11}$ reported that pterygium pressed the nasal cornea; Mark et $a l^{7}$ and Gridley and Perlman ${ }^{15}$ reported that it distorted tugging the cornea; and Oldenburg et $a l^{6}$ suggested that the observed corneal flattening in the meridian of the pterygia is produced by a pooling of tears at the pterygium apex.

Oldenburg et $a l^{6}$ reported that there were no myofibroblast cells within the pterygium tissue in their ultrastructural study. They suggested that there was no effect of traction power of the pterygium on the corneal topographic changes.

Gridley and Perlman ${ }^{15}$ reported that a case with traumatic pseudopterygium has alternate astigmatism by gaze position, and they thought that this might be related to the traction power of the pterygium. Also, Walland et al, ${ }^{16}$ in a case with recurrent pterygium, found that astigmatism reached $15 \mathrm{D}$ in the lateral gaze.

In this study carried out using a computerized corneal topography system, keratometric astigmatism at the central cornea did not increase at the temporal gaze as expected. The mean positive astigmatic axis and visual acuity did not change at the temporal gaze.

Oldenburg et $a l^{6}$ reported, in their study performed using a keratometer and a corneoscope, that the cornea became more regular following removal of pooling of tears at the pterygium apex. In our study, we observed that pterygium causes serious corneal astigmatism $(4.31 \pm 1.91 \mathrm{D})$, and this astigmatism reduces $(2.19 \pm 1.55 \mathrm{D})$ following dried pooling of tears at the pterygium apex.

We found that the cornea was flatter in nasal quadrant, and central and inferior peripheral cornea. These corneal changes returned, and the total mean refractive power significantly increased following removal of pooling of tears at the pterygium apex. Budak et $a l^{3}$ and Cinal $e a^{17}$ also reported that the cornea became more refractive after pterygium surgery. We suggested that the corneal steeping that occurred after pterygium operation could be related with the disappearance of the pooling effect of tears following pterygium excision.

As a result, we conclude that pooling of tears at the pterygium apex plays an important role, while there is no effect of traction power of the pterygium on the corneal topographical changes.

\section{References}

1 Coroneo MT. Pterygium as an indicator of ultraviolet insulation: a hypothesis. Br J Ophthalmol 1993; 77: 734-739.

2 Reinstrow SD. The conjunctiva. In: Chandler JW, Sugar J, Edelhauser HF (eds). External Diseases: Cornea, Conjunctiva, Sclera, Eyelids, Lachrymal System. Textbook of Ophthalmology. Mosby-Wolfe: London, 1995, pp 2.10-2.11.

3 Budak K, Khater TT, Friedman NJ, Koch DD. Corneal topographic changes induced by excision of perilimbal lesions. Ophthal Surg Lasers 1999; 30: 458-464.

4 Wilhelmus KR. External Disease and Cornea, Baseline and Clinical Course, Section 8. American Academy of Ophthalmology: San Francisco, CA, 1999-2000; pp 339-344.

5 Gans L. Surgical treatment of pterygium. In: Belin MW (ed). Focal Points. Clinical Modules for Ophthalmologists, Vol. 14. American Academy of Ophthalmology: San Francisco, CA, 1996, p 12.

6 Oldenburg JB, Garbus J, McDonnell JM, McDonnell PJ. Conjunctival pterygia. Mechanism of corneal topographic changes. Cornea 1990; 9: 200-204.

7 Cameron ME. Histology of pterygium: an electron microscopic study. Br J Ophthalmol 1983; 90: 36-108.

8 Pavilack MA, Halpern BE. Corneal topographic changes induced by pterygia. J Refract Surg 1995; 11: 92-95.

9 Pavilack MA, Halpern BE. Corneal topographic changes induced by pterygia. Invest Ophthalmol Vis Sci 1993; 34: 1219.

10 Lin A, Stern G. Correlation between pterygium size and induced corneal astigmatism. Cornea 1998; 17: 28-30.

11 Hansen A, Norn M. Astigmatism and surface phenomena in pterygium. Acta Ophthalmol 1980; 58: 174-181.

12 Stern GA, Lin A. Effect of pterygium excision on induced corneal topographic abnormalities. Cornea 1998; 17: 23-27.

13 Soriano JM, Jancnecht $\mathrm{P}$, Witschel $\mathrm{H}$. Effect of pterygium operation on preoperative astigmatism: prospective study. Ophthalmologe 1993; 90: 688-690. 
14 Tomidokoro A, Oshika T, Amano S, Eguchi K, Eguchi S. Quantitative analysis of regular and irregular astigmatism induced by pterygium. Cornea 1999; 18: 412-415.

15 Gridley MJ, Perlman EM. A form of variable astigmatism induced by pseudopterygium. Ophthal Surg Lasers 1986; 17: 794-795.
16 Walland MJ, Stevens JD, Steele AD. The effect of recurrent pterygium on corneal topography. Cornea 1994; 13: 463-464.

17 Cinal A, Yasar T, Demirok A, Topuz H. Effect of pterygium surgery on corneal topography. Ophthal Surg Lasers 2001; 32: 35-40. 